\title{
How to solve misplacement of a lumen-apposing metal stent during cholecystogastrostomy: immediately perform a second one!
}

A 66-year-old man was referred to our endoscopy unit because of a computed tomography (CT) scan diagnosis of a $4-\mathrm{cm}$ pancreatic head neoplasia causing malignant biliary obstruction (MBO) with a 3-cm distal common bile duct (CBD) obstruction owing to neoplastic infiltration. The patient underwent endoscopic ultrasonography (EUS) plus fine needle biopsy with macroscopic on-site evaluation (MOSE) of the specimen [1]. Subsequently an attempt to approach the major papilla for CBD drainage was performed using endoscopic retrograde cholangiopancreatography (ERCP) but was unsuccessful because of infiltration in the duodenal and papillary area. Because of gallbladder distension, we therefore decided to perform a freehand cholecystogastrostomy under EUS guidance from the anterior wall of the gastric antrum with a new $10 \times 20$-mm electrocauteryenhanced lumen-apposing metal stent (EC-LAMS; Hot-Spaxus; Taewoong Medical Co., Gimpo, Korea) [2,3]. During the EC-LAMS placement, after the device had entered the gallbladder, the distal flange was accidentally released inside the abdominal cavity, causing bile extravasation inside the peritoneum. We extracted the stent with a tooth-rat forceps and immediately performed a successful second cholecystogastrostomy ( Video 1).

In the next 24 hours, the patient did not experience abdominal pain or fever and was discharged without symptoms 3 days later. A CT scan performed 12 hours after the procedure showed a correctly placed LAMS, with a small bile extravasation inside the peritoneum ( $\mathbf{F i g} \mathbf{1} \mathbf{a}$ ). The patient received antibiotic therapy for 5 days and, 1 week after the procedure, a second CT scan was performed, which showed complete resolution of the abdominal bile extravasation ( $\mathbf{F i g} \mathbf{1} \mathbf{b}$ ). In conclusion, should misplacement of an EUS-guided LAMS occur, in referral

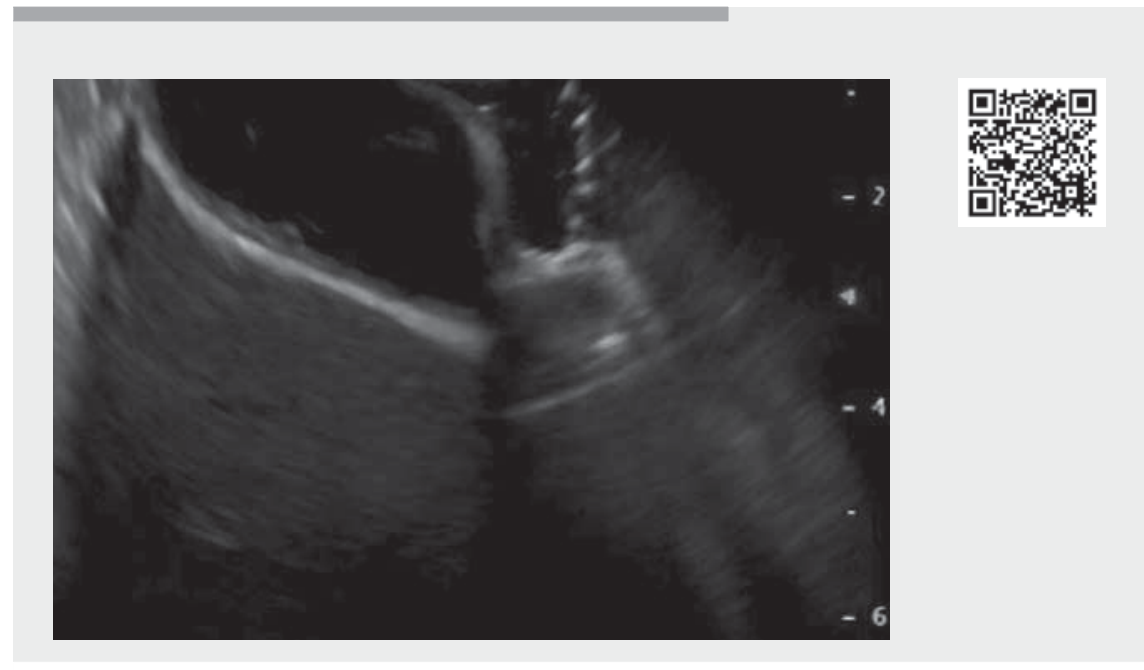

Video 1 A failed cholecystogastrostomy owing to accidental opening of the distal flange in the abdominal cavity is salvaged with an immediate second rescue cholecystogastrostomy.
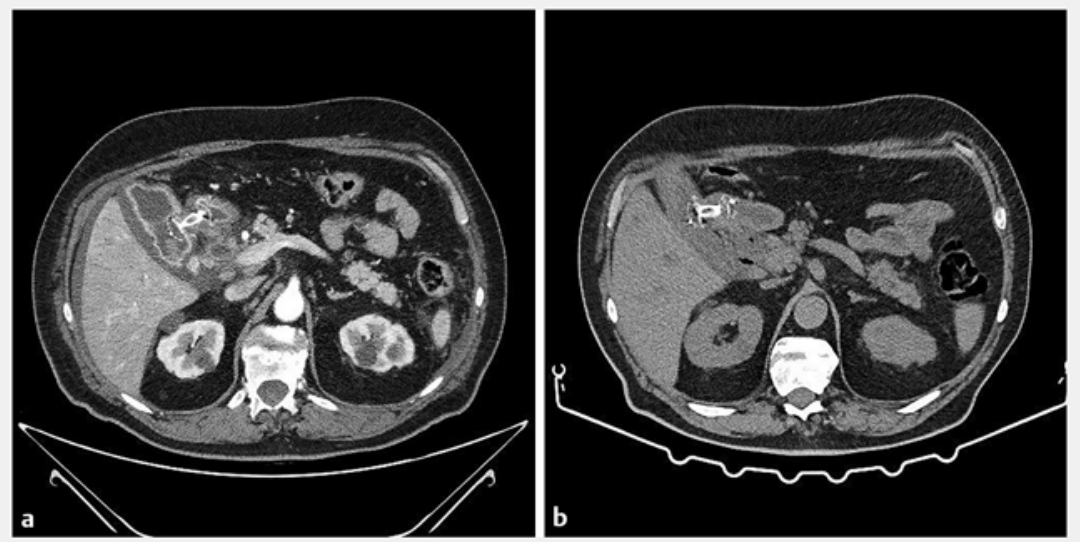

Fig. 1 Computed tomography images performed: a 12 hours after the procedure, showing bile extravasation; $\mathbf{b} 7$ days after the procedure, showing complete resolution of the abdominal bile extravasation.

centers and expert hands, an immediate second LAMS placement can avoid percutaneous or surgical intervention.

Endoscopy_UCTN_Code_CPL_1AL_2AG
Competing interests

The authors declare that they have no conflict of interest. 
Benedetto Mangiavillano ${ }^{1,2}$, Francesco Auriemma ${ }^{1}$, Danilo Paduano ${ }^{1}$, Laura Lamonaca ${ }^{1}$, Federica Spatola ${ }^{1}$, Alessandro Repici $^{2,3}$

1 Gastrointestinal Endoscopy Unit, Humanitas Mater Domini, Castellanza (VA), Italy

2 Department of Biomedical Sciences, Humanitas University, Rozzano, Milan, Italy

3 Endoscopy Unit, Humanitas Clinical and Research Center IRCCS, Rozzano, Milan, Italy

\section{Corresponding author}

\section{Benedetto Mangiavillano, MD}

Gastrointestinal Endoscopy Unit, Humanitas

- Mater Domini, Via Gerenzano n.2,

21053 Castellanza (VA), Italy

bennymangiavillano@gmail.com

\section{References}

[1] Mangiavillano B, Frazzoni L, Togliani T et al. Macroscopic on-site evaluation (MOSE) of specimens from solid lesions acquired during EUS-FNB: multicenter study and comparison between needle gauges. Endosc Int Open 2021; 9: E901-E906

[2] Mangiavillano B, Auriemma F, Bianchetti M et al. A cholecystoduodenostomy with a new type of lumen-apposing metal stent. Dig Liver Dis 2020; 1: S1590

[3] Yoo HW, Moon JH, Jo SJ et al. A novel electrocautery-enhanced delivery system for one-step endoscopic ultrasound-guided drainage of the gallbladder and bile duct using a lumen-apposing metal stent: a feasibility study. Endoscopy 2020. doi:10.1055/ a-1301-1526

\section{Bibliography}

Endoscopy 2022; 54: E421-E422

DOI 10.1055/a-1583-8947

ISSN 0013-726X

published online 8.9.2021

(c) 2021. Thieme. All rights reserved.

Georg Thieme Verlag KG, Rüdigerstraße 14,

70469 Stuttgart, Germany

\section{ENDOSCOPY E-VIDEOS \\ https://eref.thieme.de/e-videos}

口回 Endoscopy E-Videos is an open access online section, 靣社: reporting on interesting cases and new techniques in gastroenterological endoscopy. All papers include a high quality video and all contributions are freely accessible online. Processing charges apply (currently EUR 375), discounts and wavers acc. to HINARI are available.

This section has its own submission website at https://mc.manuscriptcentral.com/e-videos

\section{CORRECTION}

How to solve misplacement of a lumen-apposing metal stent during cholecystogastrostomy: immediately perform a second one! Mangiavillano B, Auriemma F, Paduano $D$ et al. How to solve misplacement of a lumen-apposing metal stent during cholecystogastrostomy: immediately perform a second one! Endoscopy, doi:10.1055/a-1583-8947 In the above-mentioned article, the institution affiliation 2 has been corrected and institution 3 was added. This was corrected in the online version on May 10, 2022. 